\title{
CARRETERAS PELIGROSAS Y LOCOS QUE CORTAN CABEZAS: DE UN CUENTO EN SÁNSCRITO DEL SIGLO XII A LA LEYENDA URBANA DE LA MUERTE DEL NOVIO
}

\author{
José Manuel PEDROSA \\ Universidad de Alcalá \\ jmpedrosa2000@yahoo.es
}

Resumen: Análisis de relatos antiguos y modernos, orientales y occidentales, protagonizados por parejas de novios o de recién casados que, en caminos o carreteras apartadas, son asaltados por locos o por salvajes.

Abstract: Analyse of folk narratives, old and modern, from Orient and from Occident, whose characters are young couples that are attacked by murdering men or savages in isolated ways and roads.

Palabras clave: Cuento. Leyenda urbana. Oriente. Occidente. Loco. Salvaje.

Key words: Narrative. Urban legend. Contemporary Legend. Orient. Occident. Mad man. Savage. 
Escritos por un tal Sivanasa, en sánscrito, al parecer en el siglo XII, los veinticinco relatos agrupados en el Vetalapañcavimshatika (o Baital-Pachisi: Los veinticinco cuentos de un Baital o de un Vampiro) se hacen eco, seguramente, de tradiciones orales antiquísimas, y figuran entre las colecciones más importantes y célebres de viejos cuentos de la India. En Occidente son conocidos gracias, sobre todo, a la antología de once de ellos que publicó Sir Richard Burton (1821-1890) en 1870, con el título de Vikram and the Vampire, or Tales of Hindu Devilry (Vikram y el Vampiro, o cuentos acerca de la diablería hindú).

Antes de atender a esta obra y al cuento que más nos interesa, hay que advertir que Burton fue un sujeto más que curioso, que reunió en una sola persona las condiciones de explorador, etnólogo (fue cofundador de la Anthropological Society de Londres), militar, diplomático (cónsul en la actual Guinea Ecuatorial, en Brasil, en Damasco, en Trieste), escritor, lingüista, hipnotizador, y muchísimas más. Se jactaba de haber recorrido los rincones más ignotos de África y de Asia, y de dominar treinta y nueve lenguas. Sirvió en la Guerra de Crimea y en la India, peregrinó disfrazado a La Meca, buscó las fuentes del Nilo y descubrió el lago Tanganica, tradujo al inglés nada menos que Las mil y una noches, el Kama Sutra, Os Lusiadas de Camõens y unos cuantos títulos más (ninguno fácil ni menor), y aún tuvo tiempo de vivir, y de morir, rodeado de todo tipo de escándalos (algunos de ellos sexuales).

A su antología del Baital-Pachisi no hay que pedirle, desde luego, fidelidad estricta al texto original (que debió alterar en no pocos detalles, siguiendo los poco escrupulosos criterios de su época). Lo admitía su viuda, Lady Isabel Burton, en el prólogo a una póstuma edición conmemorativa de 1893:

La presente traducción es algo peculiar; valiosa e interesante por el íntimo conocimiento del idioma de Sir Richard Burton. Para todos los que conocen las costumbres de Oriente, es tan ingeniosa y está tan llena de lo que popularmente se llama sorna como es posible. No contiene ni una sola página aburrida, y agradará especialmente a quienes se deleitan con lo extraño y lo sobrenatural, lo grotesco y la vida salvaje.

Mi marido sólo ofrece once de los mejores relatos, ya que pensamos que la traducción resultaría más interesante en forma abreviada (Burton, 2006: 12).

En cualquier caso, y aunque la edición de Burton no pueda ser considerada como rigurosamente filológica, ni se ajuste del todo a los criterios académicos de hoy, es cierto que sí alcanza a captar la magia y el misterio de los 
turbadores cuentos que el dicharachero vampiro se entretuvo en contar a su captor, el rajá Vikram.

El cuento noveno de la colección, el Que demuestra que la esposa de un hombre no pertenece a su cuerpo sino a su cabeza (Burton, 2006: 319-338) está protagonizado por Unmadini, hija hermosísima de un brahmán, que atraviesa por muchas y muy variadas peripecias —imposibles de detallar aquí- hasta que se casa con uno de sus pretendientes:

La boda fue espléndida, y rompió los corazones de veinticuatro rivales. A su debido tiempo, Devasharma pidió permiso a su suegro para volver a su casa, y para llevar consigo a su esposa. Concedida la petición, partió acompañado por Gunakar el soldado [antiguo pretendiente de la novia], que juró no abandonar a la pareja antes de asegurarse de que estuvieran a salvo bajo su propio techo. Ocurrió que la carretera pasaba por las cumbres de las salvajes montañas Vindhya, donde peligros de toda clase se amontonan como conchas en la playa. A un lado había rocas y afilados precipicios que hacían que el cerebro del viajero diese vueltas al mirarlos. Al otro, torrentes impetuosos rugían y relampagueaban en sus lechos de piedra negra, amenazando con destruir a quienes pretendieran cruzarlos. Primero el camino se perdía entre la tupida y espinosa maleza y las sombras negras de la selva, profundas y oscuras como el valle de la muerte. Luego las nubes de tormenta lamían la tierra con su lengua flamígera, y su voz conmovía los riscos y llenaba sus cuevas vacías. A veces, el sol calentaba tanto que las aves silvestres caían muertas en pleno vuelo. Y a cada momento los viajeros oían el barritar de los elefantes gigantes, el feroz aullido de los tigres, la escalofriante risa de la vil hiena, y el lloriqueo de los perros salvajes que seguían las huellas de la presa. Pero, sostenidos por el dios de cinco brazos, el pequeño grupo atravesó intacto todos estos peligros (Burton, 2006: 327).

En tan tétrico escenario, no es extraño que la hermosa novia se viera asaltada por un sueño terrible, que el marido interpretó como anuncio de una calamidad inminente. Devasharma saca entonces de su bolsa una madeja de hilo, la divide en tres partes — una para cada viajero-, y advierte a la joven y al soldado de que, si sufren daños, el hilo atado alrededor de la parte herida causaría la sanación instantánea, siempre que se entone al mismo tiempo un mantra resucitador:

Como predijo Devasharma, se produjo un accidente de naturaleza terrible. La mañana de aquel día, cuando llegaban a la llanura, fueron atacados por los kiratas, o tribus salvajes de las montañas. Una figura pequeña, negra y musculosa, armada con un arco y pequeñas flechas, se interpuso en su camino, haciendo gestos para que se detuvieran y entregasen sus armas. Como 
siguieron avanzando, empezó a hablar con una cháchara estridente como el canto de un pájaro asustado, sus inquietos ojuelos rojos incandescentes por la ira, y agitó su arma con furia alrededor de la cabeza. Entonces, de las rocas y matorrales a ambos lados del camino cayó una lluvia de flechas sobre los tres extraños.

El combate desigual no duró demasiado. Gunakar, el soldado, agitó su fuerte brazo derecho con efectos fatales y derribó a cerca de sesenta enemigos. Pero llegaron nuevos enjambres como abejorros furiosos zumbando alrededor del destructor de sus nidos. Y cuando Gunakar cayó, Devasharma, que le había dejado un momento para esconder a su bella esposa en el hueco de un árbol, regresó y siguió luchando sobre el cadáver de su amigo hasta que él también, superado por el número de sus enemigos, fue derribado. Entonces los salvajes, desenfundando los cuchillos, cortaron las cabezas de sus indefensos adversarios, arrancaron todos los adornos de sus cuerpos y partieron, dejando a la mujer ilesa por pura buena suerte.

Cuando Unmadini, que se había sentido más muerta que viva durante la refriega, vio que el silencio sucedía al horrendo estrépito de los chillidos y los gritos, se aventuró a salir arrastrándose de su refugio en el árbol hueco. ¿Qué fue lo que contempló? A su marido y su amigo tirados en el suelo, con las cabezas a poca distancia de sus cuerpos. Se sentó y lloró amargamente (Burton, 2006: 329-331).

La historia se complica a partir de aquí: Unmadini, engañada por las sombras de la oscuridad, «cometió un curioso error al aplicar las cabezas a los troncos equivocados» (Burton, 2006: 331), antes de pronunciar el encantamiento resucitador. Apenas devueltos a la vida, estalla el conflicto entre los dos hombres, que reclaman a Unmadini como suya, alegando uno que es la cabeza, y el otro que es el cuerpo, el que debe heredar los derechos conyugales. La pugna no encuentra perfecta solución, pues, para el vampiro que narra la historia, la bella Unmadini debía quedar unida a la cabeza de su marido, mientras que para el rajá Vikram, que escuchaba, debía ser el cuerpo el que habría de recibir ese privilegio.

Problemas somáticos y místicos aparte, lo que a nosotros más nos interesa de este tenebroso relato del Baital-Pachisi hindú del siglo XII —que, no lo olvidemos, debe hacerse eco de tradiciones orales mucho más viejas- es el motivo de la pareja de recién esposados que se adentra por un camino extraño, tenebroso y no transitado y que es atacada por incontroladas gentes salvajes que decapitan al marido y dejan viva a la mujer.

Comparemos este impactante esquema narrativo con el de las siguientes leyendas urbanas españolas, mucho más breves y concentradas, adornadas de 
mucha menos exuberancia novelesca, pero también sumamente oscuras e inquietantes. Fueron recogidas en el año 2002 en Leganés y en otros pueblos de la periferia del sur de Madrid:

[1] Una pareja de novios recién casados decidieron ir de luna de miel a un pueblo aislado. Impacientes por llegar a su destino, salieron de noche. Llegando al pueblo, cogieron un atajo. Era una carretera oscura, por donde no pasaban ni coches, ni seres vivos y lo único que había eran carteles grandes donde ponía: "Se busca a un loco que se ha escapado y es peligroso». De repente, se les pinchó la rueda. El marido fue a cambiarla, y al coger la rueda de repuesto, se dio cuenta de que estaba rota. Se le ocurrió la idea de ir a comprar una rueda al pueblo más cercano. La mujer, asustada por los carteles que estaba viendo, no quería que el marido fuera, por si se encontraba con el loco. El marido, antes de irse, le dijo a su mujer que no saliera del coche ni abriera las puertas. Pasaron horas, y el marido no llegaba. A las tres horas empezaron a sonar golpes «ipum, pum, pum!» sobre el capó del coche. Como la carretera era tan oscura, la mujer no veía nada. Siguieron sonando golpes hasta el amanecer. Llegó la policía, y le dijo a la mujer que no mirara para atrás por nada del mundo... La mujer miró y vio al loco con la cabeza de su marido golpeando contra el capó del coche «ipum, pum, pum!» (Me lo contó Vanesa Ortiz García, de 24 años, en Madrid, una noche de verano) (Pedrosa y Moratalla, 2002: 205).

[2] Estaba una familia en un atasco, cuando, en la radio, escucharon una desagradable noticia: un loco preso se había fugado y andaba suelto por la ciudad. Estaba oscureciendo. Llegó la noche y la familia seguía atrancada en el atasco. Poco a poco, el depósito de la gasolina empezó a vaciarse y, en la oscuridad de la noche, empezó a encenderse la luz de la reserva. Los coches se fueron marchando uno a uno. Para cuando el tráfico empezaba a andar con más fluidez, la gasolina del coche se había agotado totalmente. La radio seguía contando la triste historia del loco, anunciando, una y otra vez, que era muy peligroso y que, por tanto, era conveniente que nadie saliera de sus casas.

El padre tuvo que salir del coche a buscar ayuda. Al rato de marcharse, cuatro fuertes golpes sonaron en el exterior del coche, concretamente en el techo. Pocos minutos después, los golpes volvieron a sonar. La tensión aumentaba por momentos, ya que los golpes eran cada vez más fuertes y se distanciaban menos en el tiempo. Los niños y la madre empezaron a impacientarse, cuando, de pronto, los golpes empezaron a hacer que el techo se hundiera. En ese momento, llegó la policía. A los policías les temblaban las pistolas mientras apuntaban fijamente al techo del coche:

—Salgan despacio y, por lo que más quieran, no miren al techo. 
La madre, que no esperaba ver nada malo, miró y quedó horrorizada. Seguían los golpes y, sobre el techo, iluminado por los focos de la policía, estaba el loco, de rodillas y, en su mano, pudo ver la cabeza de su marido, destrozada por los golpes (Pedrosa y Moratalla, 2002: 205-206).

[3] Una pareja iba en un coche por una autopista. De repente, se encontraron con muchos policías que les impedían el paso. Les preguntaron qué sucedía, y ellos les contestaron que se había escapado un loco de un manicomio cercano, y que no podían pasar. Ellos le dijeron que necesitaban pasar, porque les faltaba gasolina. La policía les dejó pasar con la condición de que volvieran rápidamente.

Cuando ya estaban llegando a la gasolinera, se les agotó la gasolina. El chico le dijo a su novia que él se iba a la gasolinera y que, pasara lo que pasara, no saliera del coche.

Pasado un rato, a la chica le extrañó que tardara tanto y, en ese momento, empezó a escuchar golpecitos, pero no veía a nadie, a pesar de que era una noche iluminada por la luna llena. Después de mucho rato escuchando golpes, no aguantó más y salió. Cuando salió, descubrió al psicópata con la cabeza del novio puesta, como una simple careta (Pedrosa y Moratalla, 2002: 206).

[4] Un día, dos hermanos estaban en el coche; en la radio decían que un loco asesino se escapó de la cárcel esa mañana, pero ellos no le dieron mucha importancia, porque era de noche y estaban en la carretera, dentro de un coche. De repente, se les paró el coche, y el hermano mayor tuvo que irse a una gasolinera para pedir ayuda. Al rato, el hermano pequeño, que se quedó en el coche esperando, oyó unos golpes en el capó del coche y oyó decir: «ipolicía, policía!». El niño, cuando salió, vio al loco diciendo "policía», y dando golpes con la cabeza del otro hermano en el coche (Pedrosa y Moratalla, 2002: 206).

\section{La siguiente es una versión de la tradición oral de Almería:}

Esta leyenda que voy a contar llegó a mis oídos mediante amigos míos de un pueblo llamado Laujar, en la sierra almeriense.

Cuentan que un matrimonio iba en coche por la carretera, cuando tienen una avería. El hombre le dice a su mujer que hay una gasolinera cerca, así que él fue a la gasolinera a buscar ayuda. La mujer se quedó en el coche y puso la radio. En la radio escuchó que se había escapado un loco peligroso por la zona, que tuvieran cuidado. La mujer, asustada, cerró los seguros y, viendo que su marido no llegaba, se desesperaba. 
De repente, se oyeron golpes en el capó del coche. La mujer se asomó y vio al loco botando la cabeza de su marido en el techo. Después, mató a la mujer descuartizándola.

A partir de ahí, se dice que esa carretera está maldita. Es la carretera antigua del pueblo, y han tenido que hacer otra, porque la gente no pasa por ahí (Pedrosa, 2004: 213-214) ${ }^{1}$.

No es nada difícil capturar versiones de este tipo de relatos en la Babel de Internet, que, como es bien sabido, se ha convertido en depósito y correa de transmisión privilegiada del género de las leyendas urbanas. El siguiente texto, protagonizado por un loco escapado del centro psiquiátrico de Ciempozuelos (Madrid) - manicomio sobre el que tantos rumores y leyendas han circulado-, es un ejemplo muy representativo:

En Ciempozuelos hay un famoso manicomio al cual van a parar individuos de todas partes de España con todo tipo de problemas mentales, algunos de ellos son realmente peligrosos. Un sábado por la tarde corría por el pueblo el rumor de que se había escapado del manicomio un «loco» de los más trastornados y peligrosos.

Esa misma noche, una pareja de enamorados de un pueblo vecino y a punto de casarse, se disponía a volver a casa después de una noche de juerga. A un par de kilómetros de su casa el coche se les queda sin gasolina y se detiene en el arcén de la carretera. Después de estar un tiempo esperando a que alguien les pudiese socorrer sin fortuna, el novio decide acercarse a por una lata de gasolina ya que la gasolinera estaba cerca, quedándose la novia al cuidado del coche.

Habían pasado ya 2 horas, el novio aun no había regresado y estaba ya muy nerviosa cuando de repente comienza a escuchar unos sonidos fuertes, secos y entrecortados en el techo del coche, como si lo estuviesen aporreando. Aterrorizada, decide salir corriendo del coche y cuando está un tanto alejada gira la cabeza y observa que sobre el coche hay una persona dando golpes sobre el techo con una cabeza humana: LA DE SU NOVIO.

A partir de esa noche la chica cayó en una profunda crisis nerviosa que no superó y fue internada en el manicomio, donde aun permanece. Esa misma noche, un par de horas mas tarde, la Guardia Civil de Ciempozuelos detuvo al «loco» que se había escapado con las manos y la ropa completamente em-

1 Véanse otras versiones de esta misma leyenda en pp. 210-214. Téngase en cuenta, además, los textos y comentarios de Ortí y Sampere (2006: 305-308). 
papada en sangre... (http://club.telepolis.com/leyendasurbanas/historias/novio decapitado.htm).

La siguiente es una versión colombiana, de Sibate (Cundinamarca), muy semejante a la anterior, que se puede encontrar también en Internet:

La trágica historia que le sucedió a una pareja de novios cuando volvían de una fiesta. En Sibate hay un famoso manicomio al cual van a parar individuos de todas partes de Colombia con todo tipo de problemas mentales, algunos de ellos son realmente peligrosos. Un sábado por la tarde corría por el pueblo el rumor de que se había escapado del manicomio un «loco» de los más trastornados y peligrosos.

Esa misma noche, una pareja de enamorados de un pueblo vecino y a punto de casarse, se disponía a volver a casa después de una noche de juerga. A un par de kilómetros de su casa el coche se les queda sin gasolina y se detiene en el andén de la carretera. Después de estar un tiempo esperando a que alguien les pudiese socorrer, sin fortuna, el novio decide acercarse por una lata de gasolina ya que la gasolinera estaba cerca, quedándose la novia al cuidado del coche.

Habían pasado ya 2 horas, el novio aun no había regresado y estaba ya muy nerviosa cuando de repente comienza a escuchar unos sonidos fuertes, secos y entrecortados en el techo del coche, como si lo estuviesen aporreando. Aterrorizada, decide salir corriendo del coche y cuando está un tanto alejada gira la cabeza y observa que sobre el coche hay una persona dando golpes sobre el techo con una cabeza humana: LA DE SU NOVIO.

A partir de esa noche la chica cayó en una profunda crisis nerviosa que no superó y fue internada en el manicomio, donde aun permanece. Esa misma noche, un par de horas mas tarde, la policía de Sibate detuvo al «loco» que se había escapado con las manos y la ropa completamente empapada en sangre (http://www.colombiaextrema.terra.com.collocosibate.htm.).

Todas las versiones en español que hasta aquí hemos conocido son correspondencias perfectamente reconocibles de la leyenda urbana que en el mundo anglosajón - en el que existen textos documentados a partir de 1964- ha recibido el nombre de The boyfriend's death (La muerte del novio). Se conocen, además, versiones catalanas, alemanas, estadounidenses, italianas, holandesas y de tradiciones aún más exóticas, como la de Malasia²

2 Véase la versión catalana, y el detalle bibliográfico de las demás, en Pujol (2002: 200). Y también la entrada correspondiente a The boyfriend's death en la web Urban Legends Reference Pages. 
La rapidez y la eficacia con que hoy se difunde esta modalidad de relatos no hace exagerado aventurar que, a estas alturas, debemos hallarnos ante una leyenda urbana de difusión prácticamente universal.

He aquí una versión grabada entre los alumnos navajos de una reserva de Arizona (Estados Unidos) en 1976:

Maria Gale, de diez años [hablando con un grupo de condiscípulos navajos].

M. G.: Yo me sé una. Una de mis hermanas me contó que había un chico y una chica que iban a una fiesta.

R.D.: Un baile de squaws.

M. G.: Entonces... encendieron la radio y el hombre dijo: «Cuidado, hay un asesino». Y luego dijo: "Es un peludo».

Yo: ¿Un qué?

M. G.: Un peludo.

C.Y., R. D., J. D.: Un skinwalker [personaje aterrador (una especie de brujo que cambia de forma) de la mitología nativa de los navajos].

M. G. Y luego se quedaron sin gasolina. Y el chico le dijo: «Espérame aquí. Quédate en el coche mientras voy a por gasolina». Y la chica le dijo: «Vale», y se sentó en el asiento de atrás. Creo que el skinwalker mató al chico y le cortó la cabeza. Y la chica que estaba en el asiento de atrás oyó un ruido en el techo del coche y se asustó. Pero no miró arriba. Siguió oyendo el ruido y luego vio la cabeza de su novio cortada. estaba colgada boca abajo.

Jan Harold Brunvand, estudioso eminente de las leyendas urbanas, y editor de la anterior, ha escrito que:

La muerte del novio ha sido una de las historias de miedo favoritas de los adolescentes norteamericanos desde principios de la década de 1960. Muchas de las versiones incluyen efectos visuales y sonoros aterradores, como arañazos, brincos, sombras fantasmagóricas, goteos, etc. En Europa, donde la leyenda también es muy conocida, muchas veces el maníaco está sentado en la capota del coche, botando la cabeza de su víctima (Brunvand, 2002: I, 133-136).

Algunos detalles escabrosos: en muchas versiones norteamericanas, la pareja aparca el coche debajo de un árbol (debe ser curiosa casualidad que, en la vieja versión hindú, el héroe esconda a su joven esposa al abrigo 
de un árbol), y la muchacha descubre la muerte del joven cuando se da cuenta de que él o su sangre caen sobre el automóvil; en las versiones españolas y europeas, suele ser la cabeza cortada del joven, blandida una y otra vez por el loco contra el coche, la que previene a la mujer. En algunas variantes, la desventurada muchacha encanece de golpe por causa del susto. $\mathrm{Y}$ en otras, cuando los policías acuden al rescate, le advierten a gritos de que no dirija su mirada adonde está el cadáver de su pareja. Pero ella desobedece y mira - motivo bien mítico—, de igual modo que miró Orfeo al fantasma de Eurídice, o la mujer de Lot a las ciudades malditas que eran arrasadas a sus espaldas.

Sobre La muerte del novio han sido ya publicados algunos estudios extraordinariamente interesantes. Uno, por ejemplo, de Mark Glazer (1987), que analiza versiones registradas en el sur de Texas y las interpreta como una especie de simbólico castigo al novio por descuidar sus obligaciones con respecto a su coche — pues permite que se quede sin gasolina - y a su novia - pues permite que se quede sola en mitad de la nada-. Y otro de Michael Wilson (1998), que llama la atención sobre sus innumerables versiones británicas e irlandesas, y sobre el hecho de que muchos adolescentes etiqueten este relato como The Mad Axeman (El hombre del hacha), a pesar de que tal herramienta no suele ser ni siquiera mencionada. Posiblemente porque ese apodo fue puesto de moda por Frank Mitchell, un célebre presidiario inglés que alguna vez delinquió con un arma de ese tipo y que escapó de la prisión de Dartmoor en 1966, por la misma época en que la leyenda urbana de The boyfriend's death comenzó a tomar vuelo en Gran Bretaña. Aunque jamás volvieron a tenerse noticias de él, su huida provocó una histérica conmoción en todo el país, los rumores se multiplicaron, y la prensa sensacionalista contribuyó en no poca medida a difundir delirantes informaciones acerca de la extraordinaria fuerza física del fugitivo, lo que dio lugar a miedos y a rumores que pronto adquirieron la consistencia de lo arraigadamente folclórico. De modo similar, quizás, a como sucedió en España con la figura de El Lute (Eleuterio Sánchez), delincuente celebérrimo que a finales de la década de 1960 y comienzos de la de 1970 se convirtió en auténtico y perdurable mito colectivo.

Los dramáticos ecos de la leyenda urbana de La muerte del novio no han dejado de desbordar fronteras en el soporte de la voz, de Internet, de la escritura, de la prensa. También el cine y la televisión han acusado su impacto y lo han recreado en repetidas ocasiones: en títulos como Dead Poets Society (1989), Urban Legend (1998) y Sugar and Spice (2001); y en series de televisión como la norteamericana Millenium (en el episodio titulado 
The Pest House, 1998) o la británica The Vicar of Dibley (en el episodio titulado Winter, 1999) 3 .

Pero, para entender cabalmente todo este complejo de narraciones (con sus muy dinámicas versiones y diferentes desarrollos), es preciso contemplarlo a la luz de las demás que conviven con ellas en una especie de variopinta y excéntrica constelación en que se mueven, se intercambian, se asocian y se separan tipos, motivos, episodios, símbolos, funciones.

Muy similar a las narraciones del tipo de La muerte del novio, con parejas de novios viajeros, carreteras plagadas de locos y amputaciones de miembros incluidos, es el complejo de leyendas urbanas que suelen responder a la etiqueta de The hook (El garfio), y que tienen la tranquilizadora peculiaridad de que terminan mal para el agresor, y no para la pareja de inocentes víctimas. He aquí una impresionante versión norteamericana:

Esta historia la oí en una fiesta de una hermandad. Era algo así. Un chico tenía una cita con una chica realmente preciosa y en toda la noche no pudo dejar de pensar en llevársela a las afueras, aparcar el coche y pasarlo bien. Total, que por fin se la lleva a un descampado, aparca, apaga las luces, pone en la radio una música agradable; ya la tiene en el bote cuando, de repente, dan por la radio un boletín informativo que viene a decir que un maníaco sexual acaba de escaparse de un manicomio estatal y uno de sus rasgos más característicos es que tiene un garfio en lugar de una de las manos, y la chica al principio se pone muy, muy nerviosa, porque está convencida de que el sujeto en cuestión va a aparecer e intentará entrar en el coche, así que el chico cierra las puertas y le dice que no pasa nada, pero ella dice que puede romper el cristal con el garfio y tal, y no para de llorar y llorar, y se pone totalmente histérica. Y el tío al final accede a llevarla a casa, pero está muy furioso porque, claro, él tenía otros planes para la chica. Pero pone en marcha el coche y sale de allí a toda velocidad, y llegan a casa de ella, y él está muy, muy enfadado, y no piensa salir del coche para abrirle la puerta. $Y$ ella sale por su lado y, cuando sale y se vuelve, ve que hay un garfio colgando de la puerta (Brunvand, 2002: I, 121-123).

Otra leyenda relacionada con La muerte del novio y con El garfio es la que se conoce como Los dedos amputados, de la que muchos recordarán la impresionante escena que inspiró en la celebérrima película Mad Max I (1979), que dirigió George Miller y protagonizó Mel Gibson:

3 Tomo estas informaciones de la entrada correspondiente a The boyfriend's death en la web Urban Legends Reference Pages. 
Una pareja de jóvenes había salido en un clásico Volkswagen Escarabajo. Mientras estaban aparcados en una solitaria carretera rural, y tras un rato de besos y caricias, oyeron ruido al fondo de la carretera. Al levantar la vista, vieron una amenazadora pandilla de Ángeles del Infierno cortándoles el paso: todos sonreían de forma malévola y llevaban cadenas, navajas y porras. La pandilla se fue acercando al coche, rodeándoles.

La chica gritaba y el chico estaba muerto de miedo. Puso en marcha el motor y aceleró, lanzando el coche contra la barrera de agresores a toda velocidad. Los motoristas atacaron el vehículo con las cadenas e intentaron detener su carrera, pero el veloz Escarabajo los esquivó a todos.

Ya en la carretera principal, con mayor sensación de seguridad, la pareja se detuvo para comprobar los posibles daños. Y entonces vieron:

Versión A: Cuatro dedos cortados enganchados en las entradas de ventilación de la parte trasera, amputados por el ventilador.

$O$ :

Versión B: Una cadena con cuatro dedos, enganchada en el embellecedor cromado (Brunvand, 2002: 123) .

Por cierto, que otra leyenda urbana que combina los ingredientes de la pareja de novios, el viaje a lugares desconocidos y peligrosos, la desaparición de uno de ellos y el horror en que se queda sumido el otro es la que se acoge a este tipo de relato:

Yo he escuchado varias veces la historia de una pareja de novios que se va de viaje de luna de miel a algún lugar exótico, como Estambul, Túnez o Marrakech. Al llegar al hotel, el marido se dirige a la recepción para hacer la inscripción, y deja a su mujer, con las maletas, junto al taxi que les ha conducido hasta allá. Cuando regresa al taxi, ya no ve a su mujer, y a partir de entonces la pierde de vista para siempre.

Él deja su trabajo en España y se dedica sólo a buscarla, sin resultado. Al final, se vuelve loco de desesperación 5 .

${ }^{4}$ Sobre El garfio y su complejo de leyendas, véanse Dundes (1971) y Ellis (1994). Existe además otra leyenda que conviene tener en consideración, la de La autoestopista de los brazos peludos (The Hairy-Handed Hitchhiker), que puede verse en Brunvand (2002: I, 129-133). Sobre esta leyenda urbana, véase Sanderson (1981). Y acerca de todo este enrevesado complejo de narraciones, es imprescindible el trabajo de Wilson (1997).

${ }^{5}$ Recuerdo personal de José Manuel Pedrosa. Escuché esta historia cuando tenía unos 14 años, en el colegio. 
Volviendo a los locos decapitadores, o a los locos asesinos en general, merece la pena recordar que su presencia es muy notable en muchos otros tipos de leyendas urbanas -igual que lo fue en otros ámbitos del folclore, como el cuento y la leyenda tradicionales-. Quien tenga la curiosidad, por ejemplo, de explorar el grupo de leyendas que responden a la etiqueta de «Murdering Madmen», en Urban Legends Reference Pages (www.snopes.com), no tendrá ninguna dificultad en apreciar su floreciente y excéntrica diversidad. Yo me limito, ahora, a dar unos pocos y selectos ejemplos españoles:

[1] Cuenta la leyenda que, en un antiguo pueblo no muy lejano, existió un loco, el cual todas las noches entraba a las casas para complacer su deseo, que era el de cortar las cabezas a todo ser humano. Una mujer, que oyó la noticia por la radio, temió por la seguridad de su familia, y se aseguró de que todo estaba en orden, por si intentaba entrar. Hablando con su perro, le dijo que, si todo iba bien, le chupara la mano. Por la noche no debió pasar nada, ya que notó cómo la chupaba; pero, por al mañana, al ir a la cocina, encontró colgadas las cabezas de toda su familia, incluso la de su perro, con un letrero que decía: "Los locos también sabemos chupar».

Esta historia me la contó un amigo de mi abuelo, de unos ochenta años, en Navalacruz (Ávila).

[2] Un matrimonio tenía un hijo que tenía problemas mentales. Un día, el abuelo vino de visita, los padres no estaban. El niño abrió la puerta y le clavó un hacha en la cabeza. Cuando los padres vinieron y vieron lo ocurrido, ataron al niño a una silla y huyeron debido al miedo que le tenían. Pasó el tiempo y los padres regresaron, pero el niño había desaparecido. Dicen que anda vagando por las montañas de Casavieja.

[3] Tatiana me contó que unas personas estaban acampando en unas pistas de tenis en el pueblo que estaba un poco más abajo, y que todos los 28 de febrero se hacía una especie de ritual, y era que a todos los hombres les mandaban a lo alto de un monte; allí había un verdugo; y les cortaban la cabeza a las doce de la noche, siempre a los hombres nunca a las mujeres, y que después sonaba una música extraña.

[4] En un campamento, hace muchos años, unos niños hacían senderismo; iban por una carretera, y un hombre loco les asustó; siete de los niños se fueron por un lado, y los otros treinta y cinco por otro, acompañados por el monitor. Cuando los siete niños llegaron al campamento, no había nadie, y debajo de sus pies estaban las lápidas de los monitores; los niños, asustados, corrieron hacia el bosque; tanto corrían que se separaron. Cuando los monitores se enteraron, se arrepintieron, porque les querían gastar una broma, 
pero les salió mal. Transcurrida una semana, encontraron a tres de ellos (cada uno en sitios diferentes) muertos, y los otros cuatro vivos, debajo de dos árboles en forma de cruz.

Éstas son dos historias que me han contado, y siempre que las cuento y según las voy contando se me ponen los pelos de punta, y espero que a vosotros también se os hayan puesto (Pedrosa y Moratalla, 2002: 204, 208, 201 y 202).

La decapitación suele estar presente también en otro complejo de leyendas urbanas, el protagonizado en la tradición española por Verónica (prima hermana de la Bloody Mary o Mary Worth de los países anglosajones), una especie de fantasmal asesina que se aparece por la noche en los espejos:

[1] Si en un pozo de agua no potable tiras una moneda y pides un deseo, y dices tres veces «Verónica», por la noche, a las doce, aparece Verónica con un brazo de hierro y con otro de seda. Si le gusta el deseo, te acaricia con el brazo de seda, y si no le gusta el deseo, te da con el brazo de hierro y te parte la cabeza.

[2] Al parecer, hay dos versiones:

Una es que si, a las doce de la noche, te acercas a un espejo y repites el nombre de «Verónica» tres veces consecutivas, aparece la silueta de una chica con ropas blancas y largas, con una hacha en la mano, te mira a los ojos, levanta sus manos y te corta la cabeza.

Y la otra es que, si te acercas a la taza de water, y a la vez dices tres veces «Verónica», y tiras tres veces de la cadena, aparece la mano de Verónica y te agarra, y te mueres.

[3] Verónica, una chica de catorce años, que estando en el pueblo con sus amigos, hizo espiritismo en una casa abandonada. Ella no siguió las reglas de los fantasmas, se burló durante la invocación, y una silla que había en la habitación cobró vida y la golpeó mortalmente en la cabeza.

Verónica aún no descansa en paz. Su espíritu está condenado, y vaga buscando venganza entre aquellos que no saben respetar el más allá, como le sucedió en la vida real (Pedrosa y Moratalla, 2002: 176-177).

Algunas leyendas de decapitaciones y carreteras llegan a ser sumamente estrafalarias. En el capítulo segundo de The Posthumous Papers of the Pick-

${ }^{6}$ Sobre esta leyenda urbana, es imprescindible el estudio de González Terriza (2001-2002 y 2003 2004). 
wick Club (Los papeles póstumos del club Pickwick, 1836) de Charles Dickens hay un episodio que Jan Harold Brunvand ha considerado eco de un relato oral homologable con lo que hoy entendemos por una leyenda urbana:

«iLas cabezas, las cabezas, cuidado con las cabezas!» gritaba el locuaz desconocido mientras pasaban por un arco тиy bajo que en otros tiempos había sido la entrada al patio de carruajes. «Un sitio espantoso... construcción peligrosa... El otro día... cinco niños... su madre... una mujer alta, comiendo un emparedado... No se fijó en el arco... chocó... golpe... los niños miran... la cabeza de la madre... con el emparedado en la mano... sin boca para comer... sin cabeza de familia... ;terrible, terrible!» (Brunvand, 2002: 124-125)7.

El mismo Brunvand ha llamado la atención acerca de otra historia que

relata el extraordinario incidente que ocurrió en la carretera de East Lancs (A580) [número de autopista]. Al parecer un motorista iba detrás de un camión que llevaba una carga de finas planchas de acero. Decidió adelantarlo, pero al desplazarse al centro de la carretera, una plancha de acero se cayó y le decapitó. Sin embargo, la moto siguió adelantando el camión por inercia y cuando el conductor miró por la ventana y vio que le adelantaba un motorista sin cabeza, tuvo un ataque cardíaco, se salió de la carretera y se mató [...]

En otras versiones de la historia del motorista decapitado, el camionero no sólo muere de un ataque al corazón, sino que se lleva por delante a un grupo de personas congregadas en la cuneta y mata a muchas de ellas. En las variaciones norteamericanas del tema de los descuartizamientos por vehículos, puede ser un perro el que pierde la cabeza mientras viaja en un coche con la ventana abierta y las orejas al viento. El pobre Rover pierde la cabeza de forma tan rápida y limpia que el niño que va sentado a su lado en el asiento de atrás continúa acariciándolo varios kilómetros más antes de que se descubra la tragedia (Brunvand, 2002: I, 125-126).

Algunos de los elementos que flotan y circulan en todo este complejo de relatos - carreteras y parajes no transitados, cabezas cortadas, muertes terroríficas - se combinan de modos muy diversos en otros tipos de relatos que no pueden ser propiamente considerados como leyendas urbanas. En diversos lugares de Hispanoamérica tienen cierta tradición, por ejemplo, las historias acerca de seres fantasmales, sin cabeza, que se aparecen en los

7 Sobre el modo en que insertó Dickens esta leyenda urbana en el tejido de su gran novela, véase Simpson (1983). 
bosques, en los descampados, en los caminos, para causar la muerte de los viajeros. En Bolivia se cuenta lo siguiente acerca del terrorífico silbaco:

Según las tradiciones del Oriente boliviano, se cuenta que en sus lejanos bosques existe el espíritu maligno de un hombre, al cual en tiempos coloniales le cortaron la cabeza. Y se dice que en el momento que lo hicieron, de su cuerpo salió un pájaro negro ahumando. Otras personas del lugar cuentan que en las partes alejadas de la ciudad pasa un caballo galopeando con un hombre sin cabeza y que también por este lugar pasa el pájaro negro que se encuentra dibujado en algunos libros de leyendas tradicionales. Los salvajes del lugar aseguran que el hombre asesinado aparece en estos sitios porque fue allí su asesinato.

El nombre de silbaco se le da por el hecho de que el pájaro al salir rondando por el bosque silba de una manera extraña, que cualquiera dice que es el silbido de un hombre. La venganza de un espíritu es peor que la de un ser vivo (Mihara, 2004: 289) .

Y en Cuba circulan historias parecidas acerca de otro terrorífico jinete descabezado:

Dice la gente que cuando alguien ve al hombre que sale sin cabeza en un caballo blanco, va a suceder una desgracia, porque la gente que lo ve, se muere.

Dicen que sale todos los años (Victori Ramos, 1998: 88).

Si pretendiésemos hacer el seguimiento de todos los relatos que, al hilo de tal o cual motivo, esencial o periférico, se relacionan con los que han centrado nuestra atención, correríamos el riesgo de extraviarnos en los vericuetos de un laberinto sin fin. Carreteras, descampados, parejas jóvenes, locos peligrosos, amenazas de muerte, decapitaciones y otras groseras modalidades de crimen, se dan cita, en mayor o menor medida, y en órdenes y en combinaciones muy variables, en una enorme cantidad de relatos folclóricos y no folclóricos.

Atendamos, muy brevemente, al motivo de las parejas de novios o de recién casados que son objeto de acoso por parte de seres destructivos (locos, salvajes, asesinos, secuestradores, etc.). ¿A qué puede deberse que sean las parejas jóvenes víctimas tan apetecibles, y a que sujetos completamente locos o salvajes estén tan empeñados en perseguirles, y en escenarios tan dramáti-

\footnotetext{
8 Véanse otras leyendas acerca del silbaco en la misma obra, pp. 303, 304, 306, 323 y 324.
} 
camente tétricos y hostiles? Pues a que una pareja de novios, o de jóvenes esposos, es, entre otras cosas, un símbolo de fecundidad, una garantía de futuro, de continuidad, del conjunto del grupo, de toda la comunidad. Del mismo modo que lo son los niños a los que, en tantas ficciones, persiguen los ogros o las brujas, o las mujeres jóvenes raptadas por tantísimos guerreros o gigantes (o por indios pieles rojas o por psicópatas desahuciados). Los locos, o los salvajes erigidos en oponentes y en perseguidores, son, en cambio, símbolos de lo irracional, del mal por el mal, de las fuerzas oscuras de lo que no tiene control ni explicación y constituyen, por tanto, la más oscura e inquietante amenaza para cualquier comunidad.

Nuestras historias de parejas de recién casados, indefensas en escenarios aislados y amenazantes, desbaratadas por locos asesinos, son, pues, una metáfora radical, perfecta, casi cósmica, de la lucha de la fecundidad contra la muerte, del equilibrio contra el caos, del cielo contra el infierno, del bien contra el mal. De la continuidad de toda la comunidad contra su ruina. Un tipo de tragedia absolutamente impactante, con los personajes rigurosamente polarizados y el conflicto insuperablemente delineado. Y un drama con escenarios y nombres siempre diferentes, continuamente renovados, pero con un guión casi siempre común.

Recuérdese que en un camino apartado fue donde - en el ciclo narrativo paneuropeo de Flores y Blancaflor - los padres de la aún no nacida Blancaflor fueron sorprendidos por sus enemigos y donde fue cruelmente asesinado - decapitado en algunas versiones - el esposo, y cautivada la esposa:
El conde y la condesa fueron a una romería
y oscurecieron n'el monte, lo más desierto que había, el conde tendió la manta, la condesa la baía:
- Aquí tenemos de estar hasta que Dios traiga el día.
Antes que Dios traese el día se rodearon de morería.
- Entrega la condesa al moro o te ha de costar la vida.
- Yo no entrego la condesa al moro ni me ha de costar la vida.
Estando en estas palabras, la cabeza le caía, marcharon con la condesa pa la morería... (Suárez López, 1997: 516-517).

En solitarios, laberínticos y opresivos escenarios urbanos tiene lugar el rapto, por parte del loco director de un manicomio, de la inocente joven de $E l$ gabinete del doctor Caligari (1919), de Robert Wiene, y la precipitación en la locura de su joven amante. En una oscura senda selvática fue donde Tajomaru, el bandido loco y sádico, intercepta al joven matrimonio —allí mismo 
es asesinado el esposo- de Rashomon (1915), el relato corto del japonés Akutagawa Ryunosuke que llevó al cine Akira Kurosawa en 1950. En atormentadas carreteras están ambientados algunos de los crímenes más impactantes del loco asesino de la motosierra de La matanza de Texas (1974), de sus continuaciones $(1986,1991,1994)$ y de sus remakes (2003). O las terribles persecuciones, a cargo de bandas de moteros enloquecidos, que sufre la pareja de jóvenes recién casados en Mad Max I (1979) y en sus apocalípticas continuaciones $(1981,1985)$. Y en mitad de una carretera perdida en un descampado casi lunar es donde el protagonista de la película Seven (1997) descubre la cabeza de su joven esposa, decapitada por el más atrabiliario de los dementes.

Por si fuera poco, en un camino solitario y mítico fue donde Edipo encontró y donde, en un ataque de furia, mató a su enloquecido y soberbio padre. En caminos y puentes gustaba de apostarse don Quijote, lanza en ristre y presencia espantable, para amenazar a los asustados viandantes, a los que impedía pasar si no dedicaban a la inmortal Dulcinea los más encendidos elogios. Y en perdidos y nebulosos caminos tuvieron lugar algunas de las más locas y escalofriantes decapitaciones de las que se cuentan en La leyenda de Sleepy Hollow, el precioso cuento que Washington Irving escribió en 1820 y que en 1999 llevó Tim Burton al cine

Es indudable que el peligro de ser asaltados y decapitados, por locos o por salvajes, en caminos o en carreteras apartados, ha causado siempre honda inquietud en la impresionable mente humana, y que la imaginación colectiva ha atribuido a las parejas de novios o de recién casados el papel de víctimas favoritas, y a seres carentes de razón el de agresores más aficionados. Eso es lo que mostraba ya, en el remoto siglo XII, el cuento noveno del Baital-Pachisi hindú — heredero, sin duda, de una tradición oral aún más antigua-, y lo que han seguido difundiendo con machacona insistencia, a lo largo de los siglos y hasta el día de hoy, las ficciones caballerescas, las leyendas urbanas o el cine de acción.

No es posible negar que las discrepancias entre ramas y textos son a veces muy notables, que recaen en ocasiones sobre elementos o episodios esenciales, y que dificultan y emborronan gravemente cualquier intento de hallar hilos seguros en este ovillo intrincado. Es cierto, por ejemplo, que el cuento hindú no habla de locos (como hacen muchos testimonios occidentales modernos), sino de salvajes agresores. Pero también lo es que las figuras del salvaje y del loco han estado siempre estrechamente asociadas, hasta el extremo de que se han solapado muchas veces en un mismo personaje, como el Mer- 
lin silvestris o el Yvain de las ficciones medievales, que, cuando enloquecen, escapan a vivir en el bosque, el ámbito oscuro y turbador que dominan las fuerzas que escapan a la razón.

Es cierto, también, que la acumulación de elementos novelescos secundarios, casi siempre fantasiosos y discrepantes, hace difícil, en algunos casos, desentrañar las presumibles coincidencias y nexos entre ramas y textos. El cuento del Baital-Pachisi hindú es un ejemplo sobresaliente de ello, con su trama repetidamente atravesada por motivos adheridos que no parecen encontrar eco ni correspondencia en otros relatos. ¿O sí? La catástrofe del texto sánscrito está precedida por un desasosegado sueño présago de la hermosa Unmadini. En algunas ramas del Flores y Blancaflor europeo no falta otro sueño présago de quien enseguida será joven viuda y joven madre. Y tampoco las mujeres víctimas de El gabinete del doctor Caligari o de Mad Max I logran dormir tranquilas antes de que se abata sobre ellas la desgracia. En otro orden de cosas, el conflicto del cuento hindú se ve agravado cuando la atribulada esposa confunde e intercambia las cabezas de los dos hombres asesinados. El de algunas ramas del Flores y Blancaflor europeo, se complica también cuando las parteras intercambian a los dos niños - el de la desdichada viuda y el de la reina mora a la que pasa a servir - que nacen al poco del terrible suceso... Da la impresión, a veces, de que el laberinto de espejos deformantes en que se proyectan y rebotan todos los relatos nunca deja de traer débiles ecos, perdidos girones, de las palabras que antes se pronunciaron.

Cada época, cada lugar, viste sus relatos con ropajes y con adornos diferentes. Pero, atentamente escudriñados, no es difícil descubrir, bajo las diversas, a veces exóticas apariencias primeras, la comunidad de ideas, de inquietudes, de símbolos, de metáforas, y también de estructuras narrativas, que laten en el escondido corazón de muchas ellas.

No es posible reconstruir, con las frágiles cenizas que el olvido no ha llegado a aventar, sobre los precarios islotes documentales que constituyen nuestro único punto de apoyo, el presumible mapa evolutivo, la potencial geografía folclórica y literaria del tópico narrativo cuyos pasos hemos estado siguiendo. ¿Deberíamos hablar de coincidencias o de similitudes casuales entre textos? ¿O bien de intertextualidades efectivas, de entrecruzamientos de hilos subterráneos que en muy contadas ocasiones se hacen apreciables, y sólo cuando asoman a la luz por contraste con la blancura del papel o con los focos del cine?

Personalmente, cada vez creo menos en casualidades y más en la potencia vital, en la energía inconsumible, de las palabras que pasan de boca en boca, 
de lugar en lugar, de generación en generación, dejando, en los relatos que cuentan unos, las huellas indelebles de los relatos que antes pronunciaron otros.

\section{REFERENCIAS BIBLIOGRÁFICAS}

BRunvand, J. H. (2002). El fabuloso libro de las leyendas urbanas. Demasiado bueno para ser cierto, trad. M. Berastegui. Barcelona: Alba.

BURTON, R. (2006). Vikram y el vampiro: cuentos clásicos hindúes de aventuras, magia y amor, trad. S. García. Madrid: Valdemar.

Dundes, A. (1971). «On the Psychology of Legend». En American Folk Legend: A Symposium, W. D. Hand (ed.), 21-36. Berkeley-Los ÁngelesLondres: University of California Press.

ElLIS, B. (1994). «The Hook reconsidered: Problems in Classifying and Interpreting Adolescent Horror Legends». Folklore 105, 61-75.

Glazer, M. (1987). «The Cultural Adaptation of a Rumour Legend: The Boyfriend's Death in South Texas». En Perspectives on Contemporary Legend II, G. Bennet, Paul Smith y J. D. A. Widdowson (eds.), 93-108. Sheffield: Sheffield Academic Press.

GonzÁlez Terriza, A. A. (2001-2002 y 2003-2004). «Verónica, la Virgen del espejo y las tijeras: leyendas etiológicas y rituales de evocación». Estudos de Literatura Oral 7-8, 131-160 y 9-10, 129-154.

Minara, Y. M. (2004). Narrativas tradicionales del Dpto. de La Paz, Bolivia. Hirakata, Osaka, Japón: Seminario de Y. Mihara de la Universidad de Kansai Gaidai.

Ortí, A. y SAMPERe, J. (2006). Leyendas urbanas. Madrid: Martínez Roca.

Pedrosa, J. M. (2004). La autoestopista fantasma y otras leyendas urbanas españolas. Madrid: Páginas de Espuma.

Pedrosa, J. M. y Moratalla, S. (2002). La ciudad oral. Literatura tradicional urbana del sur de Madrid. Teoría, método, textos. Madrid: Comunidad de Madrid.

Pujol, J. M. (coord.) y Grup de Recerca Folklòrica d'Osona (2002). Benvingut/da al club de la SIDA, $i$ altres rumors d'actualitat. Barcelona: Generalitat de Catalunya. 
SANDERSON, S. (1981). «From Social Regulator to Art Form: Case Study of a Modern Urban Legend». ARV 37, 161-166.

Simpson, J. (1983). «Urban Legends in the Pickwick Papers». Journal of American Folklore 96: 382, 462-470.

SuÁREZ LóPEZ, J. (1997). Silva asturiana. Nueva colección de romances (1987-1994). Oviedo-Madrid: Fundación Ramón Menéndez Pidal-Real Instituto de Estudios Asturianos-Ayuntamiento de Gijón-Archivo de Música de Asturias.

Urban Legends Reference Pages (www.snopes.com).

Victori RAmos, M. ${ }^{a}$ C. (1998). Cuba: expresión literaria oral y actualidad. La Habana: Centro de Investigación y Desarrollo de la Cultura Cubana Juan Marinello.

WiLson, M. (1997). «The Hook, The Mad Axeman and The Licked Hand: Studies in Believability, Fashionability and Popular Circulation». En Performance and Practice: Oral Narrative Traditions Among Teenagers in Britain and Ireland, 41-67. Aldershot: Ashgate.

- (1998). «Legend and Life: The Boyfriend's Death and The Mad Axeman». Folklore 109, 89-95. 